\title{
FRAYÈRES ET GÉNITEURS
}

\author{
par H. GUYARD
}

Sous le titre : frayères artificielles pour Salmonidés, M. l'Ingénieur des Eaux et Forêts Chimiss a fait paraître un très intéressant article dans le Bulletin Français de Pisciculture, no 190 (Septembre 1958.)

Étant nous-même particulièrement intéressé, et depuis longtemps, par cette question, nous sommes heureux de pouvoir éventuellement contribuer à son étude par les quelques observations suivantes :

M. Chimits indique qu'une des causes de la remontée des Truites aux frayères, est qu'elles recherchent à cette époque une eau plus froide et plus oxygénée. Nous pensons qu'il s'agit là d'une erreur, que nous avons d'ailleurs déjà signalée dans un article paru dans la revue « $\mathrm{Au}$ bord de l'eau " de Septembre 1956. Dans beaucoup de rivières de plaine, en effet, l'eau est en général moins froide en amont qu'en aval, à l'époque de la fraye, soit du 15 Novembre à la fin de Janvier. C'est un fait que nous avons bien souvent constaté au cours de nombreux alevinages et qui s'explique d'ailleurs facilement, l'eau des sources étant protégée des variations de la température extérieure et se trouvant ainsi plus fraiche en été et plus chaude en hiver que celle qui a déjà accompli à l'air libre un assez long parcours. Dès lors, il est bien évident que ce n'est pas une augmentation du taux d'oxygène dissous que les Truites recherchent en remontant aux frayères. Ce point nous paraît important à préciser, car si ce n'est pas cela que les Truites désirent, c'est autre chose, que nous avons le plus grand intérêt à connaître (1).

Nous avons indiqué, dans l'article en question, qu'à notre avis les Truites exigeaient de leurs frayères les quatre qualités suivantes : clarté

(1) Cette recherche est l'objet des études poursuivies depuis une quinzaine d'années par le Laboratoire de physiologie du Muséum d'Histoire naturelle sous la direction de M. le Professeur Fontaine, membre de l'Institut. Si les facteurs internes, température, oxygénation de l'eau, etc... peuvent retentir sur certains facteurs externes au moment de la reproduction, ils ne les dominent pas, et la preuve en est l'extrême fantaisie, vis-à-vis de ces facteurs, des déplacements des Salmonidés, notamment des Saumons, au moment de leur migration. M. Fontaine pense avec raison que ce sont des différences de physiologie neuro-endocrinienne qui a conditionnent en partie le caractère migrateur d'une espèce comme les diverses modalités de cette migration chez les diverses races de Saumon ". Cette hypothèse féconde vaut évidemment pour la Truite. N. D. L. R. 
de l'eau, constances relatives de la température et du $\mathrm{pH}$, absence de prédateurs. Nous signalions toutefois qu'il devait y en avoir d'autres, ayant remarqué que, sur des gravières présentant toutes les qualités ci-dessus, certains coins étaient délaissés et d'autres régulièrement encombrés de couples.

La circulation de l'eau dans les graviers - point que l'article de M. Chimits met en évidence - est certainement d'une grande importance. Nous sommes maintenant en mesure après plusieurs années d'expériences, d'apporter à ce sujet quelques précisions. Nous avons, en effet, réalisé depuis trois ans - et pour les raisons que nous exposerons plus loin - toute une série de frayes naturelles de Truites et Saumons de fontaine sur des gravières artificielles.

Celles-ci étaient à l'origine constituées par quelque 300 litres de graviers triés, répartis sur environ deux mètres dans des caniveaux en ciment de 40 centimètres de large et de 50 centimètres de profondeur. Sur ces graviers passait un courant d'eau de 120 litres/minute environ, la hauteur d'eau au-dessus de la gravière étant de 8 à 10 centimètres.

\section{PREMIERE OBSERVATION \\ GRILLE PLACÉE a l'aval DU GANIVEAU (Fig. 1)}

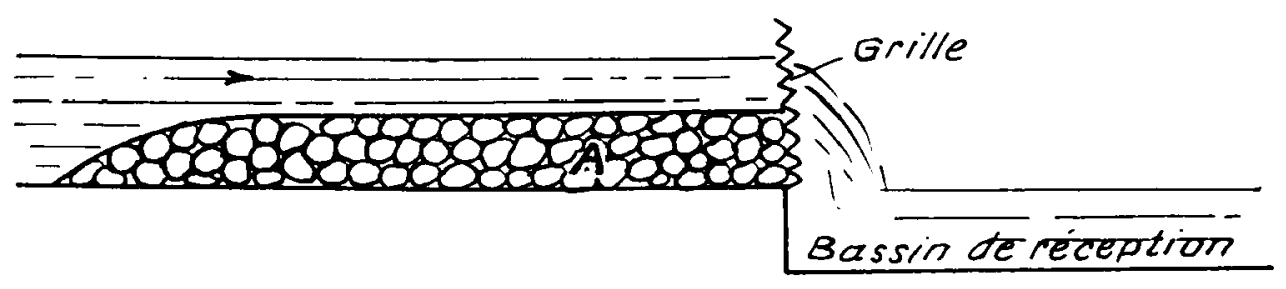

I. Position des golets avant lintroduction des Truites

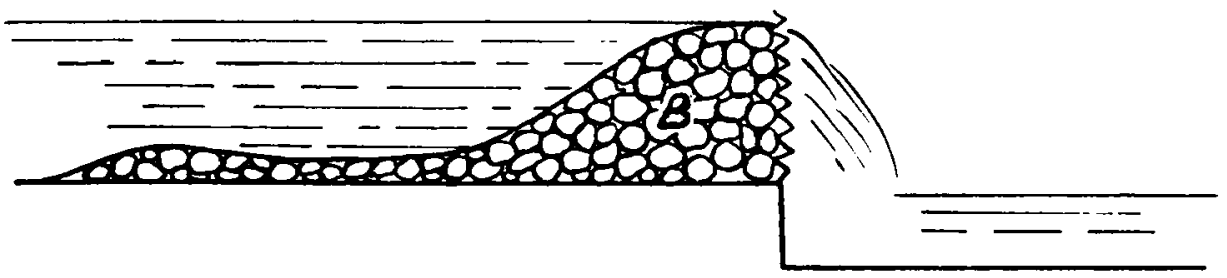

II Position après la fraye (aufs en B)

Fig. 1.

Les Truites ont creusé la partie antérieure du banc de galets pour repousser ceux-ci à la sortie, de sorte qu'ils recouvrent la grille sur toute la hauteur de sortie de l'eau et sont ainsi traversés par le courant. Tous les cufs pondus se trouvent en $B$. 
DEUXIĖME OBSERVATION. - GRILLE PLACEE LATÉRALEMENT (Fig. 2)

Même phénomène : les Truites ont disposé les galets spécialement devant la grille, de façon à ce que leur frayère soit traversée par le maximum de courant.
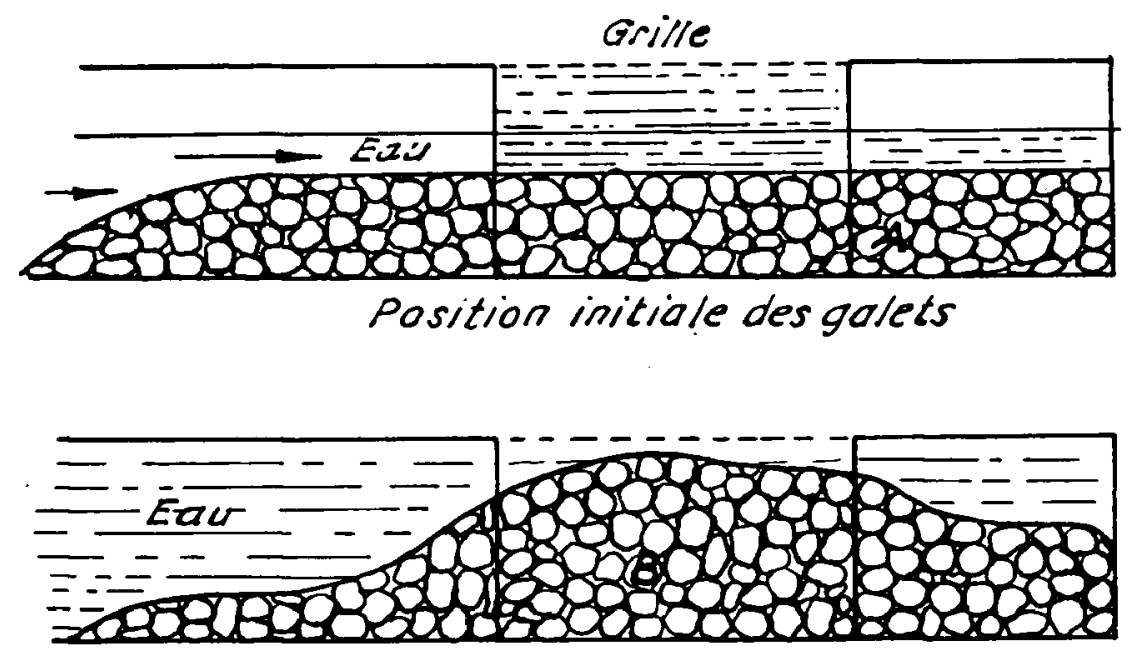

Position aprés la fraye (aufs en B).

Fig. 2.

\section{TROISIEME OBSERVATION. - FRAYERE ARTIFICIELLE A COURANT ASGENDANT (Fig. 3)}

Nous avions remarqué à plusieurs reprises que lorsqu'il y avait des sources dans le lit d'un ruisseau, formant des résurgences sousmarines dans une gravière, celle-ci devenait un lieu de prédilection pour la fraye des Truites. Nous avons pensé alors que ces dernières recherchaient de préférence les gravières traversées par un courant ascendant, celui-ci ayant probablement pour effet d'assurer un nettoyage constant des gravières. Nous avons alors installé, toujours dans le même caniveau que précédemment, une frayère artificielle "à courant ascendant " établie comme l'indique la figure 3.

Les reproducteurs déposés en aval ont remonté entre les deux barrages et ont frayé sur la gravière en B. Ils n'ont que relativement peu dérangé les galets. Quelques œufs - très peu — ont été retrouvées en A. L'incubation en $B$ a été excellente, le limon s'étant déposé au fond du caniveau, sous la grille.

Il est à remarquer, qu'en dépit du "courant contraire " (très faible il est vrai) les oufs se sont cependant insinués dans les galets, absolument comme dans une gravière ordinaire. 


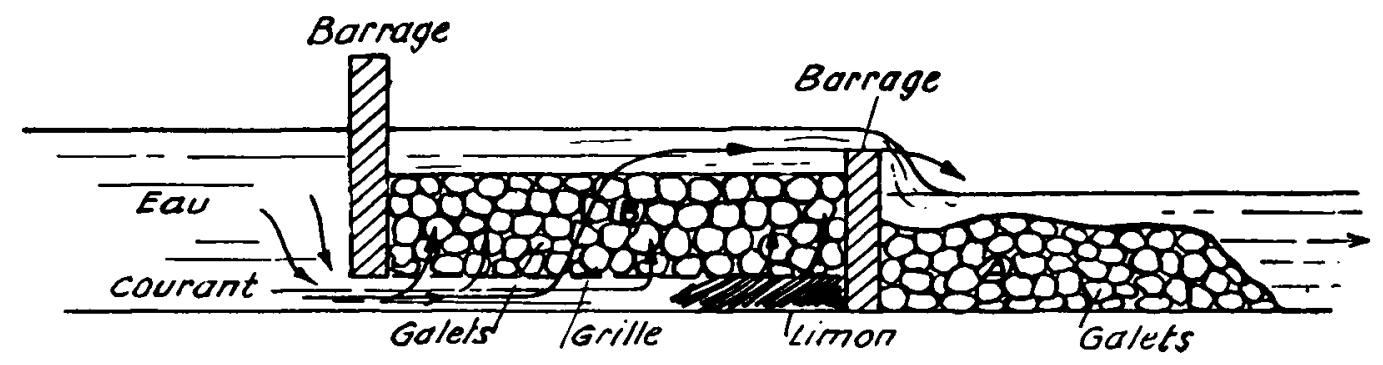

Fig. 3.

Cette expérience nous a amené à construire des incubateurs spéciaux, fondés sur le même principe et dans lesquels un très faible courant ascendant, traversant une série de claies superposées, permet d'incuber un très grand nombre d'œufs, avec un résultat excellent.

Le grand intérêt des frayères artificielles - qu'elles soient du type ordinaire ou du type ci-dessus (un peu compliqué, nous le reconnaissons) - ne réside pas seulement dans le fait qu'elles permettent un repeuplement naturel dans des rivières jusqu'alors dépourvues. C'est dans une autre idée que nous avons effectué nos recherches. Nous avons en effet été frappé par la grave épidémie des Truites de pisciculture, épidémie que le Dr. Bellet a étudiée dans le Bulletin Français de Pisciculture de juin 1958. Tout en rendant hommage à la parfaite justesse des observations du Dr. Bellet, nous ne pouvons nous empêcher de penser que cette maladie n'est pas seulement due à une alimentation exagérée et défectueuse : il y a dix ans, nous nourrissions les Truites arc-en-ciel de la façon actuellement incriminée et il n'y avait alors aucune mortalité. D'autre part, la Fario de pisciculture est jusqu'ici restée indemne. Nous avons alors pensé que, si l'alimentation était certainement en cause, puisqu'un jeûne prolongé suivi d'un régime adéquat enrayait souvent la manifestation du mal, elle n'était en quelque sorte qu'une cause seconde, la cause première n'étant peut-être qu'une " dégénérescence " de la race (1), rendant celle-ci désormais inapte à supporter les mêmes conditions de vie que naguère et probablement due, au moins pour une grande part, $\dot{a}$ la succession répétée et ininterrompue des fécondations artificielles.

La manifestation de cette "dégénérescence " serait dans ce cas particulièrement spectaculaire chez la Truite arc-en-ciel, où les dégâts matériels revêtent un caractère d'extrême gravité. Mais il nous faut remarquer que chez les autres salmonidés de pisciculture, Saumon de

(1) Les spécialistes admettent, en général, à la suite de Schaperclaus, qu'il s'agirait d'un ultra-virus, dont l'action serait évidemment favorisée par une avitaminose, mais la présence de cet ultra-virus n'a jamais été établie et le problème de l'anémie infectieuse des Truites reste entier. $N . D . L . R$. 
fontaine et Truite fario, la même cause engendrerait certains effets, qui, pour être différents, ne laisseraient pas d'être également assez sensibles.

Chez le Saumon de fontaine, il faut signaler la mortalité excessive des œufs en cours d'incubation, puis la grande fragilité des alevins après la résorption de la vésicule, enfin la décrépitude rapide des reproducteurs, dont la survie ne dépasse pas 3 ans pour les mâles et 4 pour les femelles.

Nous avons tenté, avec plus ou moins de bonheur, l'acclimatation du Saumon de fontaine dans différents cours d'eau du Morbihan. Nous avons pu constater à cette occasion que les seuls repeuplements qui ont donné un résultat appréciable sont ceux qui furent effectués par le moyen de reproducteurs prêts à frayer. Certains de ces ruisseaux ainsi repeuplés il y a 4 et 5 ans, contiennent encore du Saumon de fontaine, alors que les tentatives de repeuplement par cufs ou alevins n'ont pas donné grand'chose. Il y a là, nous semble-t-iI, une indication intéressante en faveur de notre hypothèse.

Chez les Farios, les manifestations de dégénérescence seraient moins sensibles, mais il faut justement tenir compte du fait que le cheptel géniteur des piscicultures est assez souvent enrichi par l'apport de poissons autochtones, issus de frayes naturelles, ce qui n'est évidemment le cas ni pour l'Arc-en-ciel, ni pour le Saumon de fontaine. Cependant, nous avons cru remarquer que les reproducteurs Farios provenant notamment d'œufs d'origine finoise, présentaient eux aussi un signe de dégénérescence se manifestant par un pourcentage excessif de poissons stériles, tant mâles que femelles.

Nous avons pu cette année utiliser pour la première fois des reproducteurs issus de frayes naturelles (Truites sauvages et poissons provenant de nos essais de frayères artificielles et soigneusement recueillis et conservés dans ce but). Nous avons alors constaté - bien qu'il se soit agi d'oufs de première ponte - une très considérable amélioration du taux de fécondation des œufs, passé de 60 à $90 \%$ et du taux de survie des alevins à la résorption de la vésicule. Nous n'avons pu procéder encore aux mêmes expériences sur l'Arc-en-ciel et le Saumon de fontaine, mais nous espérons pouvoir le faire dès l'année prochaine.

Quoiqu'il en soit, nous estimons que ces constatations, bien qu'encore insuffisantes et fragmentaires, peuvent nous permettre, dès maintenant, d'inviter nos collègues pisciculteurs à se constituer un cheptel de reproducteurs Arc-en-ciel issus d'œufs pondus naturellement en frayères artificielles. En admettant mème que les résultats ultérieurs ne correspondent pas à nos prévisions, il ne s'agit là que d'un petit travail, réalisable à peu de frais, et d'un procédé qui n'est susceptible d'aucune contre-indication.

Nous pensons aussi que les sociétés de Pêche se trouveront bien d'intensifier, dans la mesure du possible, les essais de repeuplement par couples de géniteurs prêts à frayer, làchés en Novembre dans des ruisseaux pourvus de bonnes gravières, naturelles ou artificielles. Cette méthode, comme le fait très justement remarquer $M$. Chrmits, ne s'oppose 
nullement aux autres. Nous ajouterons qu'elle est très simple et n'est pas plus coûteuse; de plus, elle a pour elle la logique et le bon sens : quelles que soient en effet ses connaissances, l'homme ne pénètre pas, il s'en faut, tous les secrets de la Nature et a le plus grand intérêt, quand il le peut, à la laisser agir. 